\title{
International variations in mortality among diabetic patients: the WHO Multinational Study of Vascular Disease in Diabetics*
}

\author{
J.Head and J.H. Fuller \\ Department of Comunity Medicine, University College and Middlesex School of Medicine, London, UK
}

\begin{abstract}
Summary. Mortality among 4740 diabetic men and women aged 35-55 years participating in the WHO Multinational Study of Vascular Disease in Diabetics has been studied. Ten of the original centres (Warsaw, Berlin, Havana, Arizona, Oklahoma, Hong Kong, Switzerland, London, Tokyo, Zagreb) were able to identify the life/death status of their study participants on 1 January 1983, giving an average follow-up period of six to seven years. All-cause mortality rates in males varied about threefold among the ten participating centres with the highest rates in Warsaw, Berlin and Havana and the lowest rates in Tokyo and Zagreb. All-cause mortality rates for females varied about fourfold with the highest rates in Warsaw and Oklahoma and the lowest rates in Tokyo. The
\end{abstract}

proportion of deaths ascribed to circulatory disease varied among the centres ranging from $32 \%$ for males and $0 \%$ for females in Tokyo to $67 \%$ for males and $47 \%$ for females in London. There was an excess all-cause mortality in males compared to females for all centres except Zagreb. This excess also applied to circulatory diseases in general, ischaemic heart disease in particular and occurred in both insulin-dependent and non-insulin-dependent diabetic patients. Death rates for insulin-dependent diabetic patients were generally higher than those for non-insulin-dependent patients.

Key words: Mortality, insulin-dependent diabetes, non-insulin-dependent diabetes, circulatory disease, epidemiology.
An excess mortality in diabetic patients, particularly from cardiovascular causes, has been demonstrated in many prospective studies $[1,2]$. This excess cardiovascular risk has not been explained in terms of the risk factors established for non-diabetic populations, such as hypertension, cigarette smoking and hyperlipidaemia [3]. The WHO Multinational Study of Vascular Disease in Diabetics (MSVDD) [4] confirmed previous studies in showing a marked variation in the prevalence of indicators of cardiovascular disease such as electrocardiographic (ECG) abnormalities and chest pain symptoms among 14 samples of middle-aged diabetic patients throughout the world [5].

Ten of the original 14 participating centres have been able to carry out a follow-up study for mortality in their diabetic cohorts, including a standardised assessment of cause of death. We have examined variations in mortality rates among the centres for all causes of death, circulatory disease and renal disease. We have also analysed all cause mortality by type of diabetes: insulin-dependent or noninsulin-dependent.

\section{Subjects and methods}

\section{Sample}

In each centre, samples were selected from patients aged $35-55$ already under treatment for diabetes who had been diagnosed at least one year earlier [4].

In each participating centre, a method for identifying a sampling frame of diabetic patients was chosen which would best reflect the population with diabetes in that area. Further details of the sampling method are given in previous publications of the WHO MSVDD [4,

* Prepared by the authors for the WHO multinational study group.
5]. Some centres sampled from all patients attending diabetic outpatient clinics (London, Warsaw, Hong Kong and Tokyo). In Berlin, Zagreb and Havana, the samples were selected from registers of all diabetic patients resident within a defined geographical area. The Arizona and Oklahoma patients were recruited from registers of diabetic patients belonging to identifiable ethnic groups i.e., the Pima Indians in Arizona and the American Indians in Oklahoma. The Swiss sample was selected randomly from the diabetic patients of a large number of local practitioners from all over the country.

Patients were grouped according to age (35-41; 42-48; 4955 years), duration of diabetes $(1-6 ; 7-13 ; 14$ or more years) and gender. A random sample was selected from each of these 18 agegender-duration strata. The aim was to select 28 patients from each stratum which would provide a total sample of approximately 500 patients from each centre. In this study, an insulin-dependent diabetic patient is defined on a clinical basis as one receiving insulin therapy within one year of diagnosis. The small proportion (7.5\%) of patients from Arizona thereby classed as insulin-dependent reflects the false positive error rate of this definition, since it is thought that insulin-dependent diabetes does not occur among the Pima Indians [6, 7].

\section{Mortality follow-up}

Each centre was asked to ascertain the life/death status of all the original study participants on 1 January, 1983. This information was reported to the co-ordinating centre using a standard questionnaire. If the life/death status was unknown, the reason (e.g., emigration) and the date on which the patient was last known to be alive were recorded. The ten centres included in this analysis achieved a target of $95 \%$ complete ascertainment of life/death status in their samples.

\section{Underlying cause of death}

For each deceased patient, the centres were asked to provide a copy of the death certificate, a summary of the terminal illness from hospital records and autopsy reports if these were available. 
Table 1. Numbers in sample, percentage insulin-dependent and life/death status by centre

\begin{tabular}{lcccccc}
\hline Centre & $\begin{array}{l}\text { Total } \\
\text { Number }\end{array}$ & $\begin{array}{l}\text { Percentage } \\
\text { insulin-de- } \\
\text { pendent }\end{array}$ & \multicolumn{3}{l}{ Life/Death status on 1.1.83 } \\
\cline { 4 - 7 } & & Alive & Deceased & $\begin{array}{l}\text { Un- } \\
\text { known }\end{array}$ \\
\hline Warsaw & 486 & 43.6 & 388 & $83(86)^{\mathrm{a}}$ & 15 \\
Berlin & 560 & 32.9 & 461 & $83(78)$ & 16 \\
Havana & 515 & 17.7 & 433 & $63(97)$ & 19 \\
Arizona & 241 & 7.5 & 223 & $17(100)$ & 1 \\
Oklahoma & 653 & 7.8 & 546 & $88(96)$ & 19 \\
Hong Kong & 417 & 25.2 & 348 & $50(92)$ & 19 \\
Switzerland & 533 & 39.0 & 461 & $61(92)$ & 11 \\
London & 497 & 48.9 & 444 & $42(95)$ & 11 \\
Tokyo & 436 & 13.8 & 406 & $25(100)$ & 5 \\
Zagreb & 402 & 26.1 & 370 & $30(53)$ & 2 \\
\hline Total & 4740 & 25.1 & 4080 & $542(89)$ & 118 \\
\hline
\end{tabular}

${ }^{a}$ percentage of deaths with death certification available

The underlying cause of death was assiged by a committee of four physicians (two of the investigators and two independent doctors) using all the available evidence and coded according to the 9th Revision of the International Classification of Diseases (ICD) [8]. The amount of information on cause of death varied among the centres with some providing death certificates and summaries of terminal illness or autopsy reports for almost all patients and others only providing death certificates.

\section{Statistical analysis}

Annual age-specific death rates were estimated using the number of person-years at risk in the denominator [9]. If the life/death status of a subject on 1 January 1983 was unknown but information was supplied on the date last known to be alive, then time at risk was calculated from the date of entry until date last known to be alive. Less than $2 \%(70)$ of the sample were excluded from the analyses altogether because no such information was available. Age-adjusted death rates were calculated for each centre using the direct method of standardisation. The percentage of the total sample in each agegroup (ages $35-41: 26 \% ; 42-48: 34 \% ; 49-55: 40 \%$ ) was taken to be the standard population.

\section{Results}

Table 1 shows the composition of the sample achieved in the ten centres for which mortality data is being presented. For the majority of the centres, death certificates were available for $90 \%$ or more of the deceased subjects. The average length of follow-up was between six and seven years for all centres with the exception of Arizona which had an average length of follow-up of about five years.

\section{All cause mortality}

Age-adjusted death rates for each centre are shown in Table 2. There were wide variations in mortality rates among the ten centres. Rates for men in Warsaw, Berlin and Havana were about three times higher than those for men in Tokyo and Zagreb. There were more marked differences for the women with mortality rates in Warsaw and Oklahoma being over four times higher than those in Tokyo. In all centres, with the exception of Zagreb, mortality rates were higher for males than for females. Mortality rates for diabetic men in the Warsaw, Berlin, Havana, Arizona, Switzerland, London and Tokyo cen- tres were approximately twice as high as rates for women. The increased risk for men compared with women in these centres ranged from 1.7 in Havana to 2.7 in Tokyo.

\section{Underlying cause of death}

Figure 1 shows the differences among the centres in the proportion of deaths attributable to circulatory diseases (ICD 390-459, 798.1). The proportion of deaths in this category ranged from $67 \%$ and $47 \%$ in London to $32 \%$ and $0 \%$ in Tokyo for males and females respectively. There were also variations within the category of circulatory disease. Among the men who died, ischaemic heart disease accounted for the greater proportion of deaths from circulatory disease in all centres except Hong Kong and Tokyo where strokes were more common. The proportion of stroke deaths was highest for women in Warsaw and Hong Kong. The proportion of underlying causes of death ascribed to renal disease (ICD 250.3,580-589) was higher in Hong Kong (Males: 19\%; Females: 26\%) and Tokyo (Males: 32\%; Females: 33\%) than in the other centres.

\section{Mortality from circulatory disease (ICD 390-459, 798.1)}

Among the males in the sample, the age-adjusted mortality rates for deaths due to circulatory disease were highest in Berlin (20.5 per 1000 person-years) and relatively
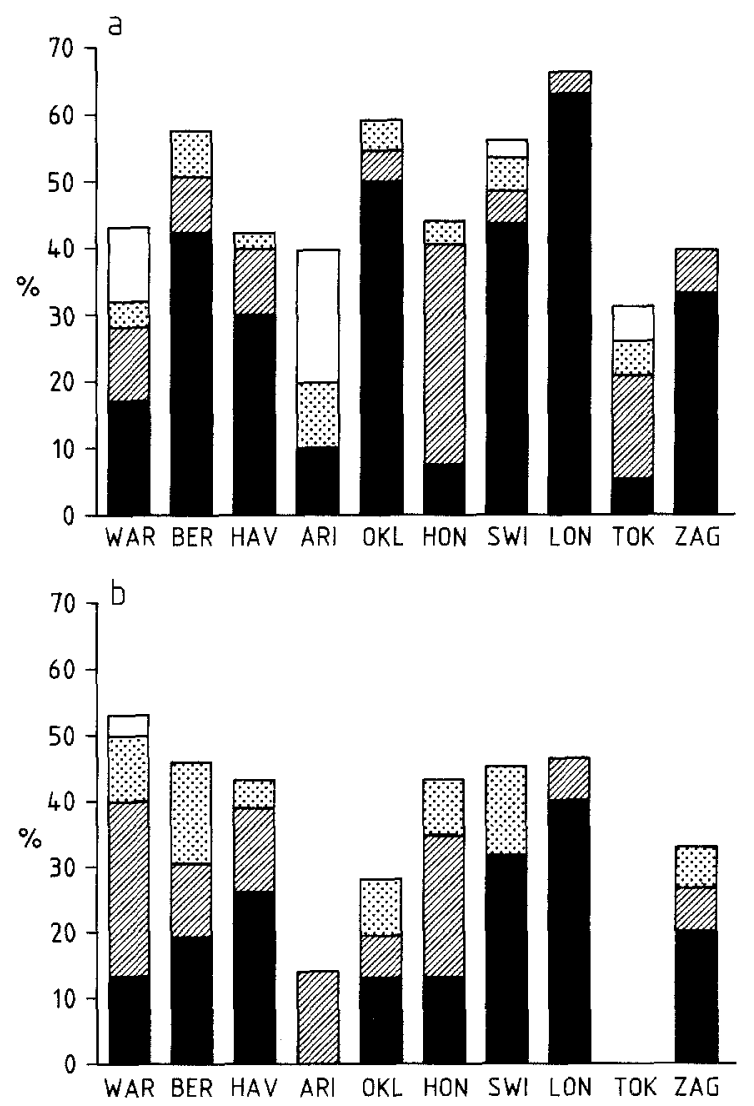

Fig. 1. Percentage of deaths attributable to circulatory disease, ischaemic heart disease $(\square)$, stroke (溉), other circulatory disease (䩮), sudden death $(\square)$, for a. males and b. females. WAR = Warsaw; BER = Berlin; HAV = Havana; ARI = Arizona; OKL = Oklahoma; HON = Hong Kong; SWI = Switzerland; $\mathrm{LON}=$ London; TOK $=$ Tokyo $; \mathrm{ZAG}=$ Zagreb 
Table 2. Age-adjusted death rates per 1000 person years (Standard Errors given in parentheses)

\begin{tabular}{llr}
\hline Centre & \multicolumn{2}{l}{ All cause } \\
\cline { 2 - 3 } & Males & Females \\
\hline Warsaw & $36.6(5.0)$ & $19.9(3.6)$ \\
Berlin & $34.8(4.6)$ & $15.2(2.9)$ \\
Havana & $29.8(4.7)$ & $17.1(3.5)$ \\
Arizona & $26.6(8.3)$ & $10.3(3.9)$ \\
Oklahoma & $25.2(3.8)$ & $19.5(2.8)$ \\
Hong Kong & $24.0(4.8)$ & $17.1(3.5)$ \\
Switzerland & $21.1(3.5)$ & $11.9(2.6)$ \\
London & $18.1(3.4)$ & $9.5(2.4)$ \\
Tokyo & $12.9(2.9)$ & $4.7(2.0)$ \\
Zagreb & $12.1(3.1)$ & $13.6(3.5)$ \\
\hline
\end{tabular}

high in Warsaw, Havana, Oklahoma, Switzerland and London (Table 3).

The rates were lower for women than for men in all centres, with the exception of Zagreb where the rates were similar. Sudden deaths were included in the circulatory disease category. In the Warsaw centre, six out of the seventeen deaths among men classified as circulatory deaths were sudden deaths. If these sudden deaths were excluded, the age-adjusted mortality rate for males would be reduced from 15.8 to11.6. Although the amount of information supplied on cause of death varied among the centres, there is no evidence that this caused any systematic bias in the determination of underlying cause of death.

\section{Mortality from ischaemic heart disease (IHD) (ICD 410-414)}

IHD mortality rates were highest in Berlin and Oklahoma for men and in Havana and Switzerland for women (Table 3). There were no IHD deaths among women in Arizona and Tokyo.

\section{Mortality from renal disease}

The category 'renal disease' includes deaths ascribed to diabetic nephropathy (ICD 250.3), as well as other types of renal disease (ICD 580-589). The numbers of deaths from this cause were small so that it is more difficult to draw conclusions from the age-adjusted death rates presented in Table 3. However, there appear to be variations in renal disease mortality among the centres with high rates for males in Warsaw, Havana and Arizona and high rates for females in Arizona and Hong Kong.

\section{Type of diabetes}

Age-adjusted all cause mortality rates for each centre and by type of diabetes are given in Figure 2. In general the death rates for insulin-dependent diabetic patients were higher than those for non-insulin-dependent diabetic patients. The total numbers of insulin-dependent-diabetic patients were small (less than 50) for some centres so death rates for these centres have been excluded. For those centres with a larger number of insulin-dependentdiabetic patients - Warsaw, Berlin, Havana, Switzerland and London - the following picture emerges. The rates for males in Warsaw, Berlin and Havana were much higher than the rates for London and Switzerland males. Among females, Berlin and Havana had relatively high mortality rates and Warsaw, Switzerland and London had relatively low rates. In all five centres, the mortality rates for males exceeded those for females.

The all cause mortality rates for non-insulin-dependent males were similar for Berlin, Arizona, Oklahoma, Hong Kong, Switzerland and London (ranging from 19.0 to 23.2 per 1000 person years at risk). The rates for Warsaw and Havana were higher (28.7 and 26.1 respectively) and the rates for Tokyo and Zagreb were much lower (6.6 and 8.9 respectively). In all centres except Zagreb the rates for females were lower than those for males. Again the rate for women in Tokyo was much lower than those in the other centres.

\section{Discussion}

Previous studies of mortality amongst diabetic subjects have shown wide international variations in death rates [1] but these analyses have usually been based on death certificates where diabetes has been assigned as the underlying cause of death. This method of analysis is known to underestimate considerably the contribution that diabetes makes to overall mortality [10] and does not permit international comparisons of causes of death in diabetic patients other than those assigned to diabetes itself.

In the WHO MSVDD, standardised methods were used to study the international variation in the prevalence of diabetic vascular complications and their possible risk factors [5]. Ten of the original participating centres have been able to ascertain the life/death status of at least $95 \%$ of their original samples at the end of a follow-up period of between six and seven years.

Table 3. Cause-specific age-adjusted death rates per 1000 person years. (Standard Errors given in parentheses)

\begin{tabular}{|c|c|c|c|c|c|c|}
\hline \multirow[t]{2}{*}{ Centre } & \multicolumn{2}{|c|}{ Circulatory $^{\mathrm{a}}$} & \multicolumn{2}{|c|}{$\begin{array}{l}\text { Ischaemic heart } \\
\text { disease }\end{array}$} & \multicolumn{2}{|c|}{ Renal disease } \\
\hline & Males & Females & Males & Females & Males & Females \\
\hline Warsaw & $\begin{array}{l}15.8 \\
(3.3)\end{array}$ & $\begin{array}{l}10.6 \\
(2.6)\end{array}$ & $\begin{array}{c}6.1 \\
(2.0)\end{array}$ & $\begin{array}{c}2.7 \\
(1.3)\end{array}$ & $\begin{array}{r}5.7 \\
(2.0)\end{array}$ & $\begin{array}{c}2.7 \\
(1.3)\end{array}$ \\
\hline Berlin & $\begin{array}{l}20.5 \\
(3.5)\end{array}$ & $\begin{array}{c}7.2 \\
(2.0)\end{array}$ & $\begin{array}{l}15.0 \\
(3.0)\end{array}$ & $\begin{array}{c}3.0 \\
(1.3)\end{array}$ & $\begin{array}{r}2.9 \\
(1.3)\end{array}$ & $(0)$ \\
\hline Havana & $\begin{array}{l}12.8 \\
(3.1)\end{array}$ & $\begin{array}{c}7.2 \\
(2.3)\end{array}$ & $\begin{array}{c}9.0 \\
(2.6)\end{array}$ & $\begin{array}{c}4.5 \\
(1.8)\end{array}$ & $\begin{array}{c}5.2 \\
(1.9)\end{array}$ & $(0)$ \\
\hline Arizona & $\begin{array}{l}11.1 \\
(5.4)\end{array}$ & $\begin{array}{c}1.3 \\
(1.3)\end{array}$ & $\begin{array}{c}2.8 \\
(2.7)\end{array}$ & $(0)$ & $\begin{array}{c}5.5 \\
(3.8)\end{array}$ & $\begin{array}{c}5.8 \\
(2.9)\end{array}$ \\
\hline Oklahoma & $\begin{array}{l}14.9 \\
(2.9)\end{array}$ & $\begin{array}{c}5.5 \\
(1.5)\end{array}$ & $\begin{array}{l}12.5 \\
(2.7)\end{array}$ & $\begin{array}{c}2.5 \\
(1.0)\end{array}$ & $\begin{array}{c}1.8 \\
(1.0)\end{array}$ & $\begin{array}{c}3.8 \\
(1.3)\end{array}$ \\
\hline Hong Kong & $\begin{array}{c}9.5 \\
(2.7)\end{array}$ & $\begin{array}{c}7.3 \\
(2.3)\end{array}$ & $\begin{array}{c}1.5 \\
(1.1)\end{array}$ & $\begin{array}{c}2.2 \\
(1.2)\end{array}$ & $\begin{array}{r}3.9 \\
(1.7)\end{array}$ & $\begin{array}{r}4.5 \\
(1.8)\end{array}$ \\
\hline Switzerland & $\begin{array}{l}12.0 \\
(2.6)\end{array}$ & $\begin{array}{c}6.0 \\
(1.9)\end{array}$ & $\begin{array}{c}9.1 \\
(2.3)\end{array}$ & $\begin{array}{c}4.4 \\
(1.7)\end{array}$ & $\begin{array}{c}1.1 \\
(0.8)\end{array}$ & $\begin{array}{r}3.8 \\
(1.5)\end{array}$ \\
\hline London & $\begin{array}{l}12.2 \\
(2.8)\end{array}$ & $\begin{array}{c}4.5 \\
(1.7)\end{array}$ & $\begin{array}{l}11.4 \\
(2.7)\end{array}$ & $\begin{array}{c}3.8 \\
(1.5)\end{array}$ & $\begin{array}{r}0.6 \\
(0.6)\end{array}$ & $\begin{array}{c}1.3 \\
(0.9)\end{array}$ \\
\hline Tokyo & $\begin{array}{c}3.6 \\
(1.6)\end{array}$ & $(0)$ & $\begin{array}{c}0.8 \\
(0.8)\end{array}$ & $(0)$ & $\begin{array}{c}4.1 \\
(1.7)\end{array}$ & $\begin{array}{c}1.5 \\
(1.1)\end{array}$ \\
\hline Zagreb & $\begin{array}{r}4.9 \\
(2.0)\end{array}$ & $\begin{array}{r}4.5 \\
(2.0)\end{array}$ & $\begin{array}{r}4.0 \\
(1.8)\end{array}$ & $\begin{array}{c}2.6 \\
(1.5)\end{array}$ & $(0)$ & $\begin{array}{c}2.9 \\
(1.7)\end{array}$ \\
\hline
\end{tabular}

a including sudden deaths (ICD 798.1) 

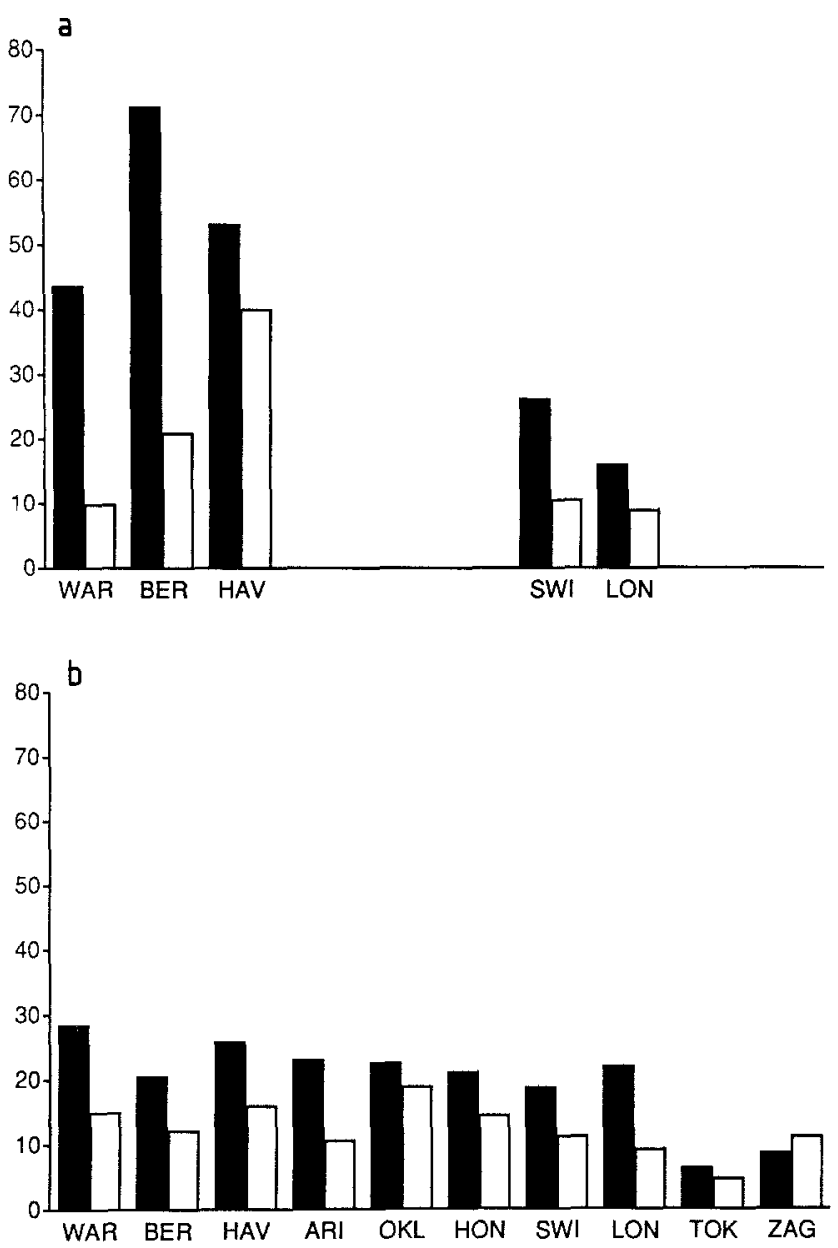

Fig.2. Age-adjusted all cause mortality rates per thousand person years, for males $(\square)$, and females $(\square)$ by centre, for a. insulin-dependent and $b$. non-insulin-dependent diabetes. Abbreviations as for Figure 1

In this follow-up study of nearly 5000 diabetic patients, all-cause mortality rates in males (Table 2 ) varied about threefold between centres with the highest rates (Warsaw and Berlin) and those with the lowest (Tokyo and Zagreb). The highest mortality rates in women occurred in Warsaw and Oklahoma, being four times the rates in Tokyo women. These variations in mortality rates probably reflect, at least in part, the known population allcause mortality differences between the countries concerned. For instance, for the age-range 40-69 years, in 1980 Polish males had 1.9 times and females had 1.6 times the all-cause mortality rates of their Japanese counterparts [11]. Some of the centres with clinic-based patient samples (e.g. London) had a higher proportion of insulindependent patients than would be expected with a population-based sample. This might be a potential source of bias if these centres had a higher proportion of severe cases with a reduced life expectancy. In fact, the London centre had comparatively low mortality rates which were similar to those found in a partly population based study in Scotland [12]. Similarly, the all-cause mortality rates in the Berlin centre were comparable to those found in a population-based study in the Erfurt district of the German Democratic Republic [13].

For the ascertainment of underlying cause of death, the mortality committee had to rely on the varying amounts of information provided by the centres. Death certificates were available for examination on $89 \%$ of all deceased patients (Table 1), and in many cases additional information from autopsy reports and clinical records was provided. In the Zagreb centre, death certificates were traced for only $53 \%$ of deceased subjects, consequently cause-specific mortality data should be interpreted with caution for this group of patients.

The proportion of deaths assigned by the study mortality committee to circulatory diseases (Fig. 1) was $40 \%$ or more in all centres except for Oklahoma and Zagreb for females and Tokyo and Arizona for both sexes, but the total number of deaths in Arizona was quite small. The London centre had the highest proportion of deaths from circulatory causes for males $(67 \%)$ and one of the highest for females ( $47 \%$ ). The corresponding proportions from a national study of diabetes mortality in England and Wales for 1975 and 1976 were similar for males (53\%) and females $(50 \%)$ in the age-range 45 to 64 years [14]. The low proportion of circulatory deaths in the Tokyo centre, with $32 \%$ for males and none for the females is similar to that found in another Japanese study of death certificates mentioning diabetes where the underlying cause of death was a circulatory disease in $27 \%$ of certificates [15]. In this same study, the proportion of deaths assigned to cerebrovascular disease $(13.9 \%$ ) was more than twice the proportion for IHD $(5.7 \%)$. Out of the ten centres, deaths from cerebrovascular disease were more frequent than those from IHD in Hong Kong and Tokyo for males and Hong Kong and Warsaw for females (Fig. 1).

The relatively high proportion of "sudden death" in the Warsaw cohort was also noted in a previous study from the same centre [16] and may partly reflect certification practices in that country. Of the five European centres, Zagreb had the lowest IHD mortality rates for both sexes (Table 3). For Yugoslavia as a whole, IHD rates were low in 1980, but are currently increasing rapidly [11]. The low IHD mortality rates in the Arizona centre (the Pima Indians) confirm previous findings in this group of a low frequency of IHD in the face of a high prevalence of diabetes [17]. This contrasts with the high IHD mortality rates in the diabetic Oklahoma Indians which are similar to those for most European centres.

For young patients with insulin-dependent diabetes, renal disease is an important cause of death [10] accounting in one study for more than one half of deaths occurring between the ages of 20 and 29 years [18]. In the present study of middle-aged diabetic patients, death rates for renal disease exceeded those for IHD in Arizona, Hong Kong and Tokyo for both sexes and in Zagreb for females only (Table 3 ).

A major feature of the mortality findings in this study of 4740 middle-aged diabetic patients is the excess allcause mortality in males compared to females for all centres except Zagreb. This male excess also applies to deaths ascribed to circulatory diseases in general and IHD in particular, and is also a feature of the analysis of all-cause mortality by type of diabetes (Fig. 2). These findings do not support some interpretations of previous studies which imply that mortality rates in female diabetic subjects equal or even exceed those in male diabetic subjects, particularly for those patients with non-insulin-dependent 
diabetes [2]. However, statements of this kind have often been based on the comparison of excess risks of mortality in male and female diabetic patients compared to the general population. Direct comparison of our results with other studies which do compare mortality rates in male and female diabetic subjects are difficult because of differences in the composition of study populations, particularly in respect of age and type of diabetes.

One study in Edinburgh showed that death rates in female diabetic patients were virtually equal to those for male diabetic patients across the whole age-range [19]. An analysis of mortality during a nine year follow-up period of diabetic subjects aged $40-50$ years in the United States NHANES1 study indicated that mortality rates for all causes and for IHD were greater for men than women [20]. Since the number of insulin-dependent patients was rather small in several centres, this analysis has concentrated on comparisons of mortality rates with both types of diabetes combined (Tables 2 and 3 ). However, the typespecific mortality data (Fig. 2) generally confirms the findings of the combined analysis in terms of the male/female differences and ranking of the centres for mortality rates.

This follow-up study of ten cohorts of diabetic patients has indicated wide international variations in patterns of mortality which need to be explained in terms of the exposures of the group to lifestyle, environmental and genetic influences. Some of this information will come from further analyses of this study relating measured baseline factors to the subsequent mortality outcomes described here, and may well parallel similar variations in mortality (especially IHD-related) affecting the corresponding general, non-diabetic populations.

Acknowledgements. The assistance of Ms. L. Stevens and Ms. S. Collins in the preparation of this paper is gratefully aknowledged.

List of centres and investigators:

1. London. United Kingdom (LON) Investigators: J.H.Fuller, R. J.Jarrett, H. Keen, N. Morrish, P. J. Watkins

2. Bern. Switzerland (SWI) Investigator: A. Teuscher

3. Warsaw. Poland (WAR) Investigators: A. Czyzyk, D. Janeczko, A. Krolewski

4. Berlin. GDR (BER) Investigators: M.Raskovic, V.Schliack, K.P. Ratzmann

5. Zagreb. Yugoslavia (ZAG) Investigators: A.Skrabalo, I.Aganovic, A. Stavljenic

6. Hong Kong (HON) Investigators: R. T. T. Young, J. Ma

7. Tokyo. Japan (TOK) Investigators: K. Kosaka, E. Miki

8. Havana. Cuba (HAV) Investigators: O. Mateo de Acosta,

O.Diaz, S. Amaro, M. Hang, X. Quesda, A. Hernandez Yero

9. Oklahoma. USA (OKL) Investigator: E. Lee

10. Pheonix, Arizona. USA (ARI) Investigators: P.H.Bennett, D.J.Pettitt

Mortality Committee: K. Ball, E. Jepson, N. Morrish, J. Fuller (London)

Statistician: J.Head (London)

\section{References}

1. West KM (1978) Epidemiology of diabetes and its vascular lesions. Elsevier, New York, pp 159-189

2. Panzram G (1987) Mortality and survival in Type 2 (non insulindependent) diabetes mellitus. Diabetologia 30: 123-131
3. Fuller JH, Shipley MJ, Rose G, Jarrett RJ, Keen H (1983) Mortality from coronary heart disease and stroke in relation to degree glycaemia: the Whitehall Study. Br Med J 287: 867-870

4. Jarrett RJ, Keen H, Grabauskas V (1979) The WHO Multinational Study of Vascular Disease in Diabetes: 1. general description. Diabetes Care 2: 175-186

5. Diabetes Drafting Group (1985) Prevalence of small and large vessel disease in diabetic patients from 14 centres. The World Health Organisation multinational study of vascular disease in diabetics. Diabetologia 28: 615-640

6. Katzeff HL, Savage PJ, Barclay-White B, Nagulesparan M, Bennett PH (1985) C-Peptide measurement in the differentiation of Type 1 (insulin-dependent) and Type 2 (non-insulin-dependent) diabetes mellitus. Diabetologia 28:264-268

7. Savage PJ, Bennett PH, Senter RG and Miller M (1979) Prevalence of diabetes in young Pima Indians. Diabetes 28: 937-942

8. World Health Organisation (1977) Manual of the international statistical classification of diseases, injuries, and causes of death, 9th Revision. WHO Geneva

9. Breslow NE and Day NE (1987) Statistical methods in cancer research. Vol II - The design and analysis of cohort studies. IARC Scientific Publications No 82, Lyon

10. Fuller JH (1985) Causes of death in diabetes mellitus. Horm Metab Res [Suppl] 15:3-9

11. Vemura K, Pisa Z (1985) Recent trends in cardiovascular disease mortality in 27 industrialized countries. World health statistics quarterly $38: 142-162$

12. Waugh NR, Dallas JH, Jung RT, Newton RW (1989) Mortality in a cohort of diabetic patients. Causes and relative risks. Diabetologia 32: 103-104

13. Panzram G, Zabel-Langhennig R (1981) Prognosis of diabetes mellitus in a geographically defined population. Diabetologia 20: 587-591

14. Fuller JH, Elford J, Goldblatt P, Adelstein AM (1983) Diabetes mortality: new light on an underestimated public health problem. Diabetologia 24:336-341

15. Sasaki A, Horiuchi N, Hasegawa K, Vehara M (1985) Causes of death in Japanese diabetics. A 20-year study of death certificates. J Chron Dis 38: 655-661

16. Krolewski AS, Czyzyk A, Janeczko D, Kopczynski J (1977) Mortality from cardiovascular diseases among diabetics. Diabetologia 13: 345-350

17. Howard BV, Lisse JR, Knowler WC, Davies MP, Pettitt DJ, Bennett PH (1982) Diabetes and atherosclerosis in the Pima Indians. Mount Sinai J Med 49: 169-175

18. Dorman JS, LaPorte RE, Kuller LH, Cruickshanks KJ, Orchard TJ, Wagener DK, Becker DJ, Cavender DE, Drash AL (1984) The Pittsburg insulin-dependent diabetes mellitus (IDDM) morbidity and mortality study. Mortality results. Diabetes 33: 271276

19. Shenfield GM, Elton RA, Bhalla IP, Duncan LJP (1979) Diabetic Mortality in Edinburgh. Diabete et Metabolisme (Paris) 5: 149158

20. Kleinman JC, Donahue RP, Harris MI, Finucane FF, Madans JH, Brock DB (1988) Mortality amoung diabetics in a national sample. Am J Epidemiol 128:389-401

Received: 23 October 1989

and in revised form: 26 February 1990

Dr. J.H. Fuller

Department of Comunity Medicine

University College and Middlesex School of Medicine

66-72 Gower Street

London WC1E 6EA

UK 